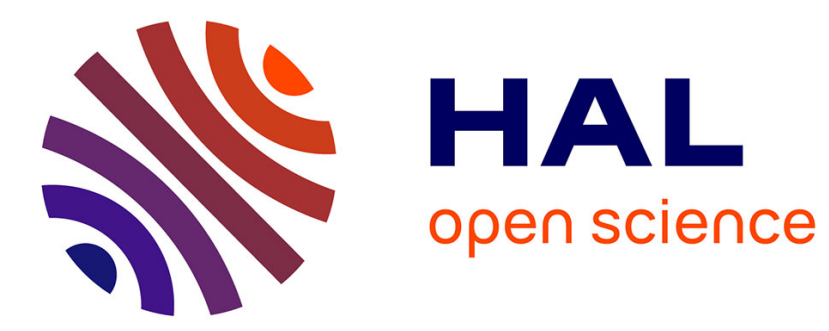

\title{
Identification of soil parameters by inverse analysis
}

\author{
Rachid Zentar, Pierre-Yves Hicher, Gérard Moulin
}

\section{To cite this version:}

Rachid Zentar, Pierre-Yves Hicher, Gérard Moulin. Identification of soil parameters by inverse analysis. Computers and Geotechnics, 2001, 28 (2), pp.129-14. 10.1016/S0266-352X(00)00020-3 . hal01006942

\section{HAL Id: hal-01006942 \\ https://hal.science/hal-01006942}

Submitted on 8 Apr 2017

HAL is a multi-disciplinary open access archive for the deposit and dissemination of scientific research documents, whether they are published or not. The documents may come from teaching and research institutions in France or abroad, or from public or private research centers.
L'archive ouverte pluridisciplinaire HAL, est destinée au dépôt et à la diffusion de documents scientifiques de niveau recherche, publiés ou non, émanant des établissements d'enseignement et de recherche français ou étrangers, des laboratoires publics ou privés. 


\title{
Identification of soil parameters by inverse analysis
}

\author{
R. Zentar, P.Y. Hicher, G. Moulin \\ Laboratoire de Génie Civil Nantes-Saint Nazaire, Ecole Centrale de Nantes, \\ BP 9210144321 Nantes Cedex 3, France
}

This paper presents a methodology for identifying soil parameters that takes into account different constitutive equations. The procedure, applied here to identify the modified CamClay parameters from a pressuremeter curve, is based on an inverse analysis approach, which consists of minimizing the function representing the difference between the experimental data and the data obtained by integrating the model along the loading path in in-situ testing. The numerical process implemented here is based on the interaction of two numerical tools; an optimization code (SiDoLo) and a general finite element code (CESAR-LCPC).

\section{Introduction}

The increasing use of finite elements method in geotechnics design has also to be accompanied by appropriate methods in order to identify the parameters of the adopted soil model.

These parameters are generally assessed on the basis of laboratory test results. However, some bias in the values of the parameters can be introduced because of the disturbance to the samples due to boring, extraction and transport. In order to overcome these difficulties, it is recommended to carry out in-situ tests. Furthermore, in-situ testing is now far more developed in the industrial sector because of their cost effectiveness.

Among in-situ tests, the pressuremeter test consists in studying the expansion of a cylindrical cavity within the soil.

There are different ways of interpreting the pressuremeter test results. They can be divided into three categories: 
- those based on empirical or semi-empirical relationships between soil properties and pressuremeter parameters [1-5];

- those based on the theoretical development of cylindrical cavity expansion solutions [1,6-11];

- and those based on numerical simulations of the test [12-15].

In practice, semi-empirical methods are preferred, although in some cases it is possible to apply theoretical methods for cavity expansion. The analytical methods are developed for linear and non linear elastic material, perfectly plastic incompressible material, strain-hardening and strain-softening incompressible material, and dilating material. During the past few decades, increased research work has allowed improved constitutive models to be developed which describe in a more accurate fashion the stress-strain behaviour of soils. However, these models, when interpreting pressuremeter tests, require the use of numerical solutions.

In this paper, we propose an alternative method that is based on an inverse analysis technique which we applied in order to identify the constitutive parameters of the modified Cam-Clay model. For this purpose two codes are used. The first one, SiDoLo, is a parameter optimization tool. The second one, CESAR-LCPC, is a finite elements code directed to geomechanics. The SiDoLo code (SiDoLo: Simulation and iDentification of constitutive models) is a general simulation and optimization code. The greater part of the code is strictly reserved for optimization, whereas a few subroutines are available for performing simple simulations directly within the code. The initial version of the code is described by Pilvin [16]. The CESAR-LCPC code is a general finite elements code, which has been developed at the LCPC Laboratoire Central des Ponts et Chaussées (LCPC). Several plastic and viscoplastic constitutive equations have been implemented in the code.

First, we describe the inverse analysis method and the numerical tools we used, secondly, we present the algorithm of resolution of the inverse problem. The performance of the computation system is then illustrated by an example of how the modified Cam-Clay parameters can be identified from pressuremeter test results.

\section{Methodology and numerical tools}

If we wish to calculate the response $(R)$ of a system including the constitutive model $(M)$ and its parameters $(m)$ subjected to the actions $(X)$, we would call it the direct problem (Fig. 1).

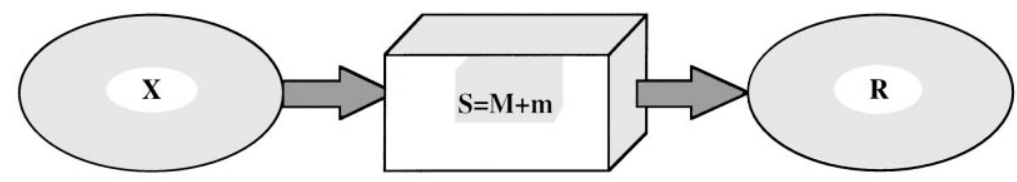

Fig. 1. Resolution of the direct problem. 
However, if part of the system $(S)$ were unknown to us, we would have to consider the inverse problem (Fig. 2). In the present case, no information about the parameters $(m)$ of the constitutive model is available. In compensation, it is necessary to have complementary data concerning the response $(R)$ in order to determine the unknown information.

The determination of the parameters of the constitutive model from the pressuremeter test consists in solving the following inverse problem: to find a set of parameters $(m)$ which minimize the difference between the experimental data [here the pressuremeter curve defined as the applied pressure $(p)$ versus the cavity wall deformation $\left(u_{\mathrm{a}} / a\right)$ ] and the results of the calculation from a given set of parameters. This problem is classically defined by a function which evaluates, for a given set of parameters, the discrepancy between the model prediction and the experimental data. The formal expression of this function is:

$$
L_{n}(P)=\frac{1}{t_{1}-t_{0}} \int\left\|R^{*}(t)-R(P, t)\right\| \mathrm{d} t
$$

where the symbol $\|.$.$\| represents a norm in the space of the observable variables,$ $\left(t_{1}-t_{0}\right)$ the length of observation and $\left[R^{*}(t)-R(P, t)\right]$, the difference between experimental data and calculation results from a given set of model parameters. While the measurements were carried out at discrete moments, the integral in Eq. (1) can be replaced by a sum and the length of observation by the number of measurements. Using the Euclidean norm and introducing a diagonal weighting matrix $D$, Eq. (1) becomes:

$$
L_{n}(P)=\frac{1}{M_{n}} \sum_{i}^{M_{q n}}\left(R_{i}^{*}-R_{i}\right)^{T} D\left(R_{i}^{*}-R_{i}\right)
$$

A diagonal weighting matrix $D$ is introduced to transform the observable variables into adimensional quantities. The quality of the measure is taken into account at this level by choosing as diagonal terms in this matrix the square of the inverse of the error estimation within the measure of each variable.

The algorithm used to resolve the non-linear optimisation problem [Eq. (2)], combines two classical minimisation techniques: the steepest descent method at the beginning of the process, in order to improve the initial guessing of the parameters, and a variant of the Levenberg-Marquardt method [17] in order to accelerate the convergence in the final phase of the identification.

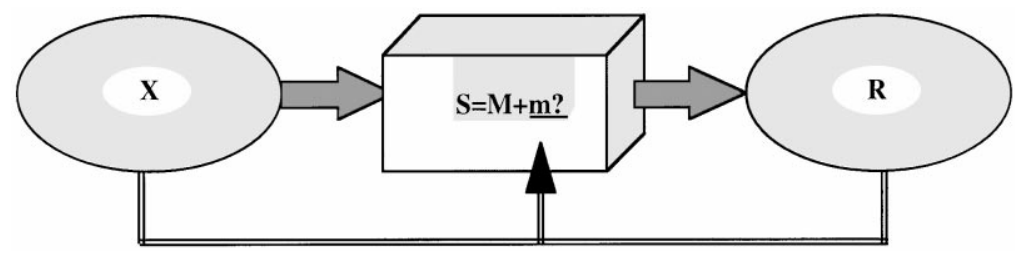

Fig. 2. Resolution of the inverse problem. 
The evaluation of the gradient, in SiDoLo optimisation code [16], is performed numerically. This last feature is important, as it allows the user to work with a totally disconnected program to evaluate the response of the model, without any kind of modification.

The numerical method used for the resolution of the non linear optimisation problem formulated as an inverse problem to identify constitutive model parameters is schematically presented in Fig. 3. This method is composed of an optimization code (SiDoLo), a finite element code (CESAR-LCPC), and an interface, whose functions are the following:

- reading the new coefficients proposed by the optimization code,

- updating the data file for the finite element code and running the simulation problem,

- reading the results and computing the new values of the observable variables used in the following iteration of the optimization procedure.

\section{Numerical modelling of a pressuremeter test}

The problem of the cylindrical cavity expansion was treated, through a modified Cam-Clay model [18], in view of interpreting pressuremeter tests performed in a clayey soil.

The modified Cam-Clay model version used in the present study is a linear elastic, plastic model. The elastic part includes two parameters: the Young's modulus, $E$, and the Poisson's ratio, $v$. The plastic part includes the slope of the critical state line in the $q, p^{\prime}$ diagram $(M)$, the parameter $\beta$, which gouverns the amplitude of the plastic volumetric strain, and can be related to the classical Cam-Clay model parameters by

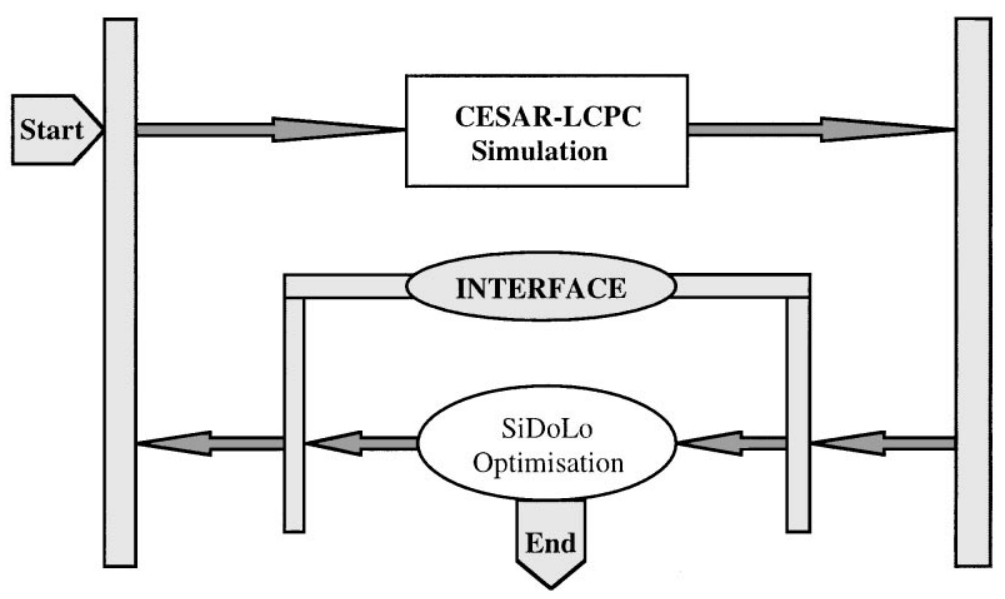

Fig. 3. Numerical process to identify relationship parameters. 
$\beta=(\lambda-\kappa), p_{\mathrm{c} 0}^{\prime}$ which is the initial value of the hardening variable $p_{\mathrm{c}}^{\prime}$ and depends on the initial void ratio $e_{0}$. In order to calculate stress and pore pressure changes in the soil caused by the expansion of the pressuremeter cavity, a coupled analysis was carried out. During this analysis, the soil was considered as saturated and the soil permeability was kept constant during the expansion test. The initial stress state was defined by $\sigma_{\mathrm{v} 0}^{\prime}, \sigma_{\mathrm{r} 0}^{\prime}=\sigma_{\theta 0}^{\prime}$. The required parameters for this analysis are summarised in Table 1.

Loading conditions around the probe were modelled as an axisymmetric problem in plane strain conditions. The dimensions for the problem are shown in Fig. 4. The probe, with radius, $a$, applies the pressure on the cavity wall. The soil boundaries considered for the numerical simulations are far enough from the probe to ensure that they do not affect the measurements, as shown by Nahra and Frank [19] and Acar et al. [20], and thus can be regarded as fixed boundaries. For simplicity, symmetry in the horizontal plane was assumed. With reference to the middle point of the membrane, the dimensions of the solid section to be considered are $30 a$ width and unit height. The soil around the probe is modelled using a mesh of 304 nodes and 81 eight-node isoparametric elements, with additional degrees of freedom for assessing the pore pressure.

Table 1

Modified Cam-Clay parameters

\begin{tabular}{ll}
\hline$E$ & Young's modulus \\
$v$ & Poisson's coefficient \\
$\beta=(\lambda-\kappa)$ & $\lambda$ defined as the slope of the consolidation line in the $e$ - $\ln (p)$ plane \\
& $\kappa$ defined as the slope of the swelling line in the $e-\ln (p)$ plane \\
$M$ & The slope of the critical state line in the $p-q$ plane \\
$p_{\mathrm{c} 0}^{\prime}$ & Preconsolidation pressure \\
$k_{\mathrm{r}}, k_{\mathrm{z}}$ & Radial and vertical soil permeability \\
$\sigma_{\mathrm{v} 0}^{\prime}, \sigma_{\mathrm{r} 0}^{\prime} \sigma^{\prime}=\sigma_{\theta 0}^{\prime}$ & Initial effective vertical, radial and orthoradial stress \\
\hline
\end{tabular}

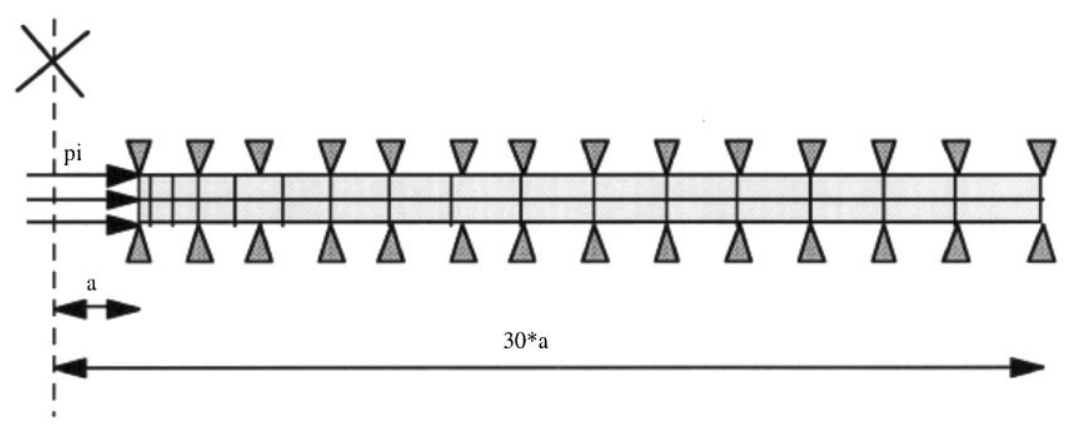

Fig. 4. Axial symmetric model of a soil thickness unit in the vertical plane (simplified mesh). 


\section{Influence of Cam-Clay parameters on the numerical results}

From the pressuremeter curve, we intend to determine several parameters of the modified Cam-Clay model. It is evident, however, that from one curve an important number of parameters is impossible to determine. That is why, before testing the numerical process developed here to identify the modified Cam-Clay parameters from pressuremeter tests, it is necessary to know which parameters can be easily determined from this test, that is, which parameter can affect the numerical response in a significant way.

The first calculation, called the reference calculation, is performed with the set of parameter values as presented in Table 2. These values are representative of a natural soft clay. In all analyses, the permeability ratio $k_{\mathrm{r}} / k_{\mathrm{z}}$ is assumed to be 1 .

In order to examine their effects on the calculated pressuremeter curve, we present, for each Cam-Clay parameter $\left(E, v, \beta, M, p_{\mathrm{c} 0}^{\prime}\right)$, the comparison between the curve obtained with the reference set (Table 2) and the curve obtained by changing the value of one parameter by $50 \%$, all the other parameters being kept equal to the reference value (Fig. 5).

This study shows that the calculation is greatly affected by the variation of Young's modulus, $E$, by the preconsolidation pressure, $p_{\mathrm{c} 0}^{\prime}$, and by the critical state constant $M$; it is slightly affected by the variation of Poisson's ratio, $v$ and not affected by the value of $\beta$.

Taking into account these results, the numerical process developed above was then tested in order to identify the Cam-Clay parameters affecting the pressuremeter curve calculation, i.e. $E, M$ and $p_{\mathrm{c} 0}^{\prime}$.

\section{Validation procedure}

In order to avoid all the problems derived from the capacity of the modified CamClay model to describe the soil behaviour and from the uncertainties on the soil characteristics, we propose to base the validation of the methodology at first on the numerical curve obtained with the reference set of parameters, which is considered as the result of a real pressuremeter test.

In the first place, we used the proposed procedure to determine one parameter. All the other parameters are kept at their reference values (Table 2) while we try to determine one parameter by allocating it an initial value different by $50 \%$ from the reference value.

Table 2

Parameter values of the simulation procedure

\begin{tabular}{lllllllllll}
\hline $\begin{array}{l}E \\
(\mathrm{kPa})\end{array}$ & $v$ & $\begin{array}{l}G \\
(\mathrm{kPa})\end{array}$ & $\lambda$ & $\kappa$ & $M$ & $\Gamma_{0}$ & $\begin{array}{l}p_{\mathrm{c} 0}^{\prime} \\
\mathrm{kPa})\end{array}$ & $\begin{array}{l}k_{\mathrm{r}}=k_{\mathrm{z}} \\
\mathrm{m} / \mathrm{s}\end{array}$ & $\begin{array}{l}\sigma_{\mathrm{r} 0}^{\prime}=\sigma_{\theta 0}^{\prime} \\
(\mathrm{kPa})\end{array}$ & $\begin{array}{l}\sigma_{\mathrm{v} 0}^{\prime} \\
(\mathrm{kPa})\end{array}$ \\
\hline 1000 & 0.3 & 384 & 1.0 & 0.1 & 1.2 & 2.0 & 80 & $10^{-9}$ & 50 & 60 \\
\hline
\end{tabular}




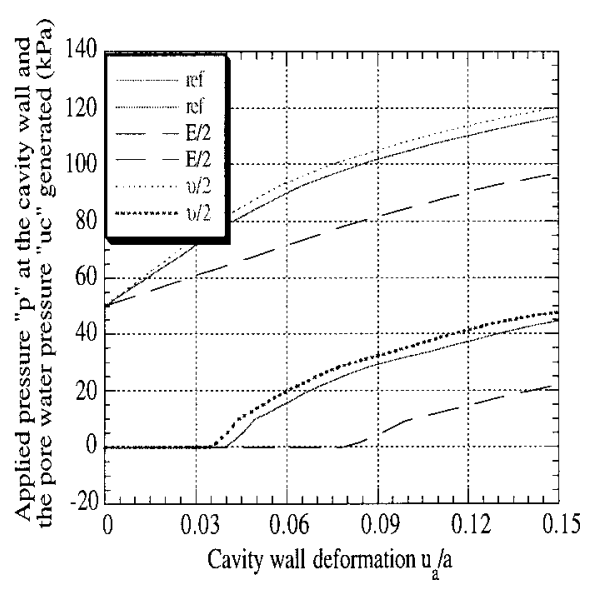

$-\mathrm{a}-\mathrm{E}$ and $v$ effects

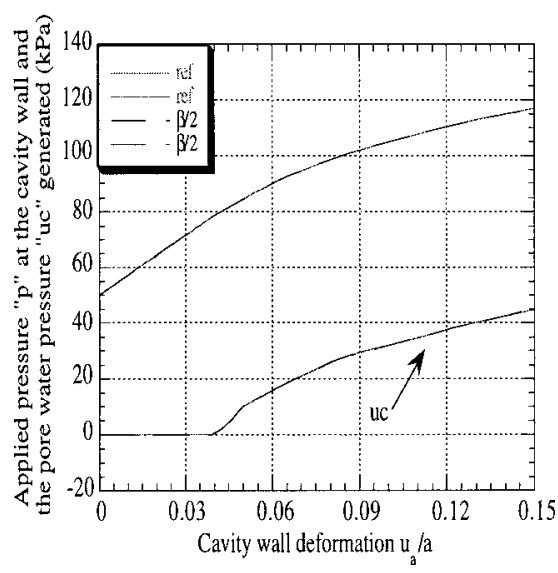

-b- $\beta$ effects

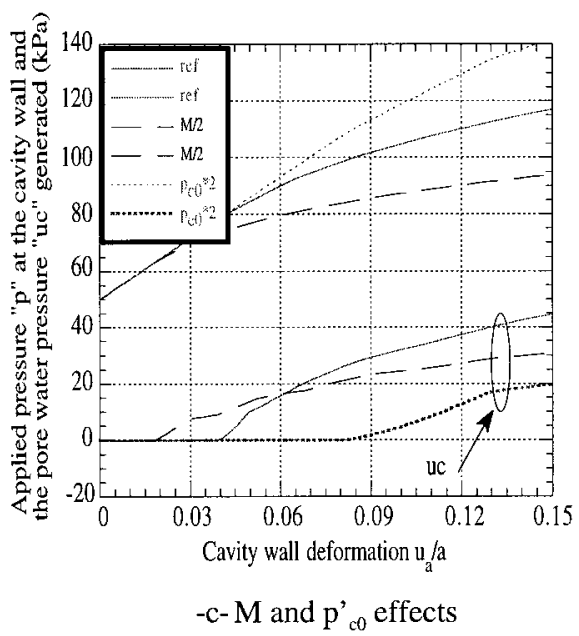

Fig. 5. Modified Cam-Clay parameter effects on the pressuremeter curve.

We observe that a satisfactory determination of the unknown parameter is achieved, the calculation taking only few iterations.

For example, to determine the preconsolidation pressure starting with an initial value of $40 \mathrm{kPa}$, we obtain the real value of $80 \mathrm{kPa}$ after 12 iterations. The determination of the Young's modulus $E$, and of the critical state constant $M$ produce the same good results (Fig. 6).

Secondly, we made an attempt to use our procedure to determine the parameter pairs: $(E, v) ;\left(E, p_{\mathrm{c} 0}^{\prime}\right) ;(E, M) ;\left(v, p_{\mathrm{c} 0}^{\prime}\right) ;(v, M) ;\left(p_{\mathrm{c} 0}^{\prime}, M\right)$. All the other parameters are kept at the reference values (Table 2), while we try to determine the two other parameters, whose initial values were different by $50 \%$ from there reference values. 
We note that the proposed procedure made it possible to obtain with accuracy the reference curve and the reference values for the parameter pairs $\left(E, p_{\mathrm{c} 0}^{\prime}\right) ;(E, M) ;(v$, $\left.p_{\mathrm{c} 0}^{\prime}\right) ;(v, M)($ Fig. $7 \mathrm{a}-\mathrm{d})$.

For the determination of the pair $(E, v)$, the calculated curve reproduces accurately the reference curve (Fig. 7e), but the parameter values determined are different from the reference values (deduced parameters: $E=923 \mathrm{kPa}, \nu=0.2$ ).

This result can be justified by the fact that the pressuremeter test is a deviatoric test, and thus, the stress-strain relationship of the cavity wall is governed by the shear modulus $G$.

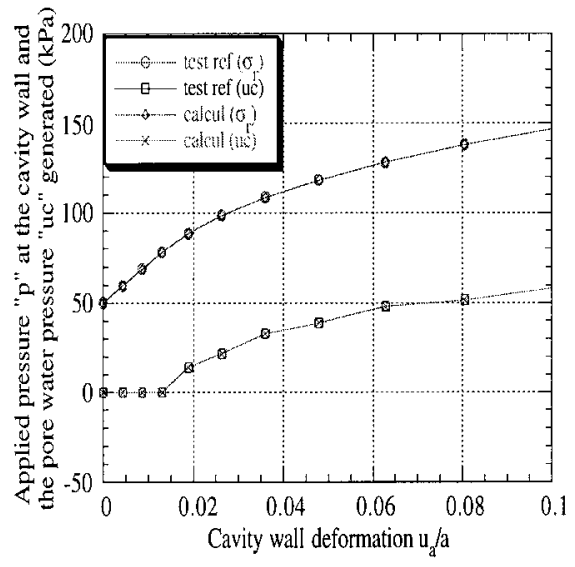

-(a)- Identification of M.

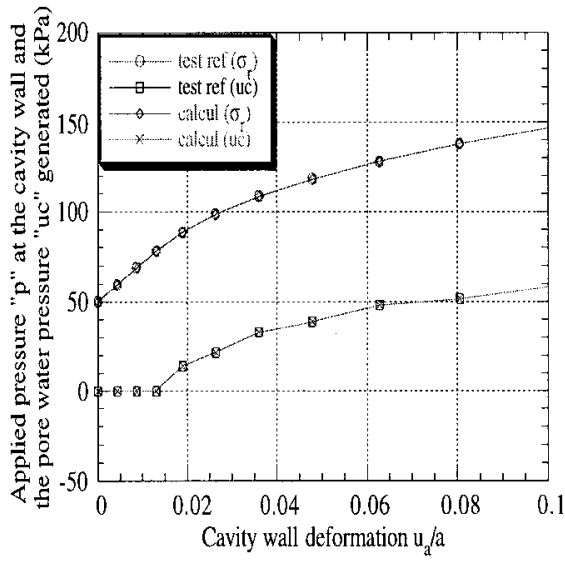

-(b)- Identification of $\mathrm{p}^{\prime}{ }_{\mathrm{c} 0}$.

Fig. 6. Application results of the numerical process to identify $M$ and $p_{\mathrm{c} 0}^{\prime}$.

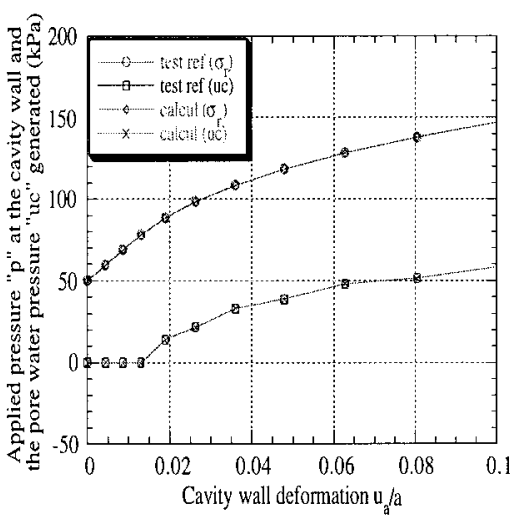

-(a)- Identification of (E, M) couples.

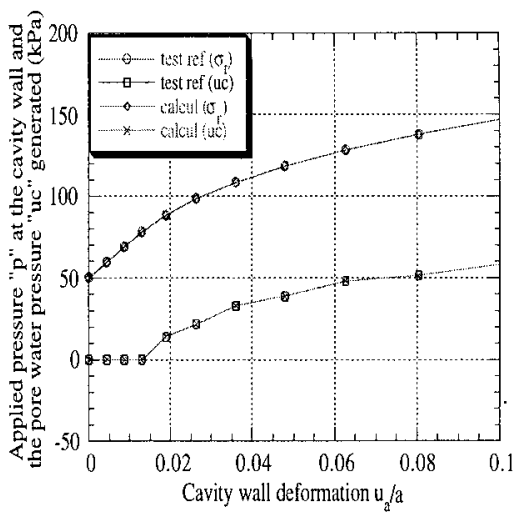

-(b)- Identification of (E, $\left.\mathrm{p}^{\prime}{ }_{\mathrm{c} 0}\right)$ couples.

Fig. 7(a,b). Results of the identification of the parameter pairs. 


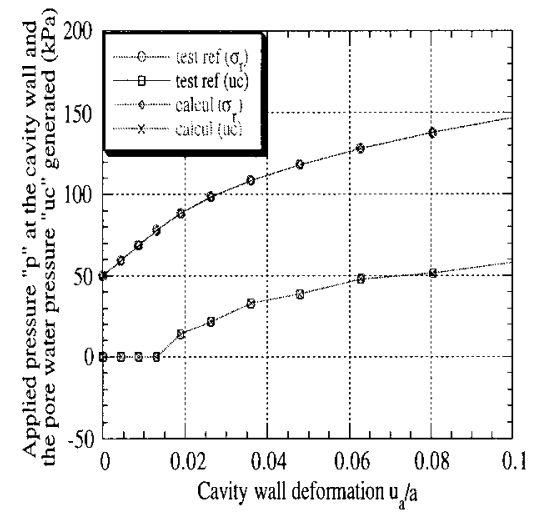

-(c)- Identification of the $(v, M)$ pair.

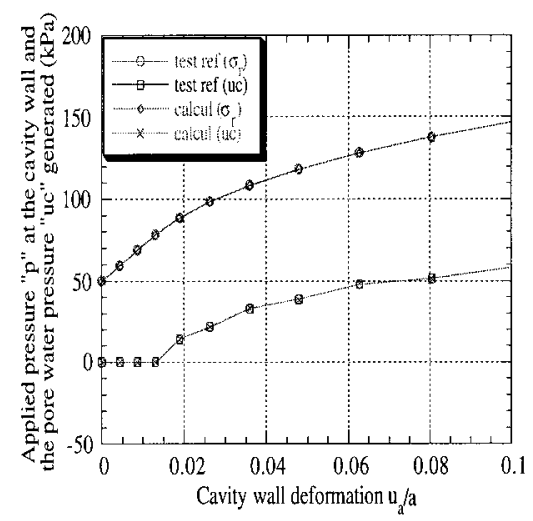

-(e)- Identification of the (E, v) pair.

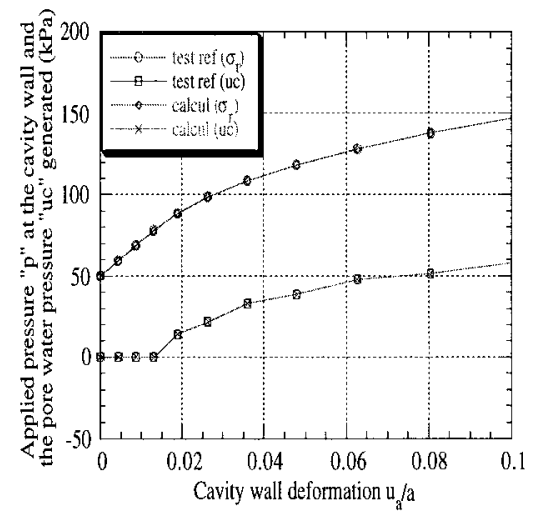

-(d)-Identification of the $\left(v, p_{c 0}^{\prime}\right)$ pair.

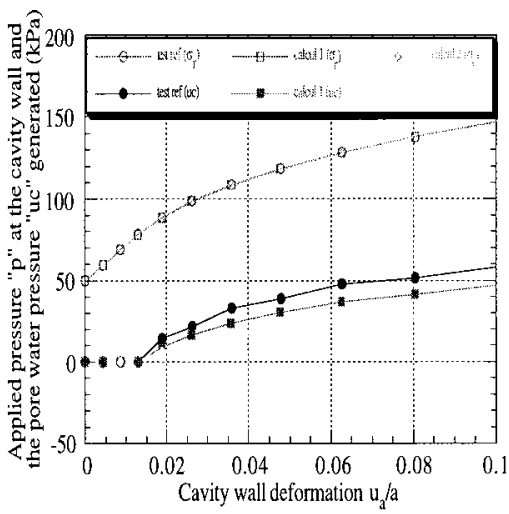

-(f)- Identification of the (M, $\left.\mathrm{p}^{\prime}{ }_{c 0}\right)$ pair.

Fig. 7(c-f). Results of the identification of the parameter pairs.

$$
G=E /\left(2^{*}(1+v)\right)
$$

Thus, an infinite number of $(E, v)$ parameter pairs corresponding to the same value of the shear modulus $G$ can minimize the distance between the reference curve and the calculated curve, as long as Eq. (3) is verified. If we calculate, from the $(E, v)$ value obtained after the optimization procedure, the value of the shear modulus, we obtain exactly the reference value $(G=384.6 \mathrm{kPa})$.

For the determination of the pair $\left(p_{\mathrm{c} 0}^{\prime}, M\right)$, the calculated pressuremeter curve reproduces accurately the reference curve (Fig. 7f), but the optimized parameter values are different from the reference values. Moreover, as shown in Table 4, for two different initial values of $M$ and $p_{\mathrm{c} 0}^{\prime}$, the parameter values obtained, according to inverse calculation, are different. We can notice that the difference obtained between the calculated and the reference values affects the pore water pressure curve. 
Table 4

Initial and final values after back calculation to identify the $\left(M, p_{\mathrm{c} 0}^{\prime}\right)$ pair

\begin{tabular}{lcccccc}
\hline & \multicolumn{3}{l}{ Initial values } & & & \multicolumn{2}{l}{ Final values (after back calculation) } & \\
\cline { 2 - 3 } Parameters & Calculus 1 & Calculus 2 & & Calculus 1 & Calculus 2 & Reference \\
\hline$M$ & 0.6 & 0.8 & & 0.63 & 0.93 & 1.2 \\
$p_{\mathrm{c} 0}^{\prime}(\mathrm{kPa})$ & 160 & 100 & & 157.5 & 103 & 80 \\
\hline
\end{tabular}

Therefore, in order to overcome this difficulty, we intend to introduce the pore water pressure data as complementary information in the numerical process to identify $M$ and $p_{\mathrm{c} 0}^{\prime}$.

In these conditions, it is possible, with the same initial values presented in Table 4, to reach the reference values of $M$ and $p_{\mathrm{c} 0}^{\prime}$ after a few iterations. The two references curves (pressuremeter curve and pore pressure evolution) are accurately reproduced (Fig. 8).

Thus, by introducing the pore water pressure as complementary information, we could uncouple the influence of the two parameters $M$ and $p_{\mathrm{c} 0}^{\prime}$. The origin of the coupling between the parameters $M$ and $p_{\mathrm{c} 0}^{\prime}$ can be explained by the fact that the soil behavior is gouverned by the effective stresses, while the optimization process is driven by the knowledge of the total stress at the cavity wall. Under these conditions several couples $M, p_{\mathrm{c} 0}^{\prime}$ can produce the same numerical results in terms of total stress, i.e. the pressure-volume change of the cavity relationship, but all the solutions correspond to different effective stress paths. If the effective stress condition at the cavity wall are imposed by the pore pressure evolution, the optimization procedure leads in that case to the determination of a sole couple $M, p_{\mathrm{c} 0}^{\prime}$ corresponding to the reference values.

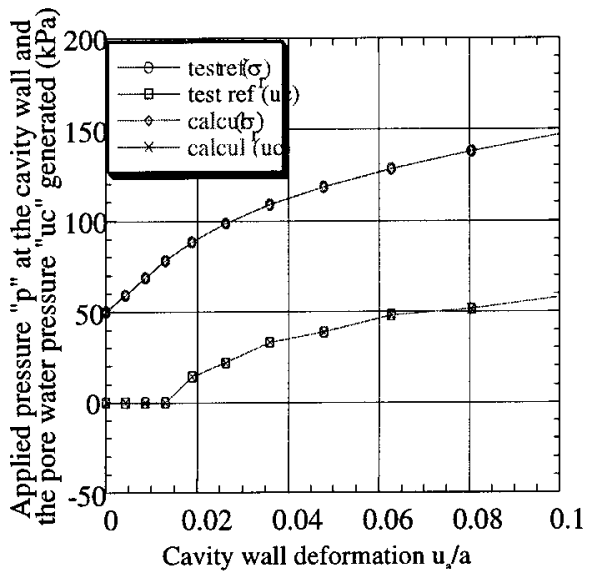

Fig. 8. Result of the back calculation of the pressuremeter test taking into account the porewater pressure as complementary information. 


\section{Application to pressuremeter tests on Saint-Herblain Clay}

The application of the inverse method to interpret pressuremeter test has shown that from an ideal pressuremeter test, we are able to identify several parameters of the modified Cam-Clay model. In the ideal case, wherever the information about pore water pressure is available, we showed that three parameters can be identified: the shear modulus $G$, the preconsolisolidation pressure $p_{\mathrm{c} 0}^{\prime}$ and the critical state constant $M$. In practice however, the measurement of the pore water pressure is often not available, so in this case only two parameters can be identified. We decided to concentrate on the determination of the shear modulus $G$ and of the critical state constant $M$. The preconsolidation pressure, $p_{\mathrm{c} 0}^{\prime}$, the gradient of the swelling line, $\kappa$, and the gradient of the normal consolidation line, $\lambda$ can be identified from onedimensional consolidation tests.

The studied site, named Saint-Herblain (in the vicinity of Nantes) is situated in the Loire Palaeolithic period. It is constituted by modern river clayey alluvium deposits. This clay is characterised by a high plasticity index and is slightly or moderately organic and overconsolidated at the surface. At the studied depth $(6.50-7.50 \mathrm{~m})$, one pressuremeter test and two one-dimensional consolidation test were performed. The pressuremeter test was performed at a depth of $7.00 \mathrm{~m}$. The equipment used was a Ménard pressuremeter. The drilling of the borehole was done under bentonitic mud injection, in order to reduce the soil decompression around the cavity.

The two one-dimensional consolidation tests were performed on samples between 7.30 and $7.38 \mathrm{~m}$. At this depth, the clay is slightly overconsolidated (OCR=1.6). Table 5 summarises the physical characteristics of the clay specimen.

The one-dimensional consolidation apparatus used in this study was modified so that the pore pressure could be monitored and measured during the test. The initial pore pressure was considered to be equal to the in-situ pore pressure. Lateral stresses could also be measured during the test.

The one-dimensional consolidation curves for the two specimens are presented in Fig. 9a. and b. On the same graphs, the difference between the pore water pressure generated at the base of the specimen (ub) and the back pressure applied (uc) is reported. To derive the soil parameters from these curves, the procedure recommended by LCPC was used [21].

The different parameters deduced from the two one-dimensional consolidation curves are presented in Table 6.

Table 5

Physical characteristics of Saint-Herblain clay samples

\begin{tabular}{lcr}
\hline Physical characteristic & Specimen 1 & Specimen 2 \\
\hline Depth $(\mathrm{m})$ & $7.30-7.34$ & $7.34-7.38$ \\
Water content $(\%)$ & 134.3 & 145.4 \\
Dry unit weight $\left(\mathrm{KN} / \mathrm{m}^{3}\right)$ & 5.59 & 5.34 \\
Unit weight $\left(\mathrm{KN} / \mathrm{m}^{3}\right)$ & 13.09 & 13.20 \\
\hline
\end{tabular}



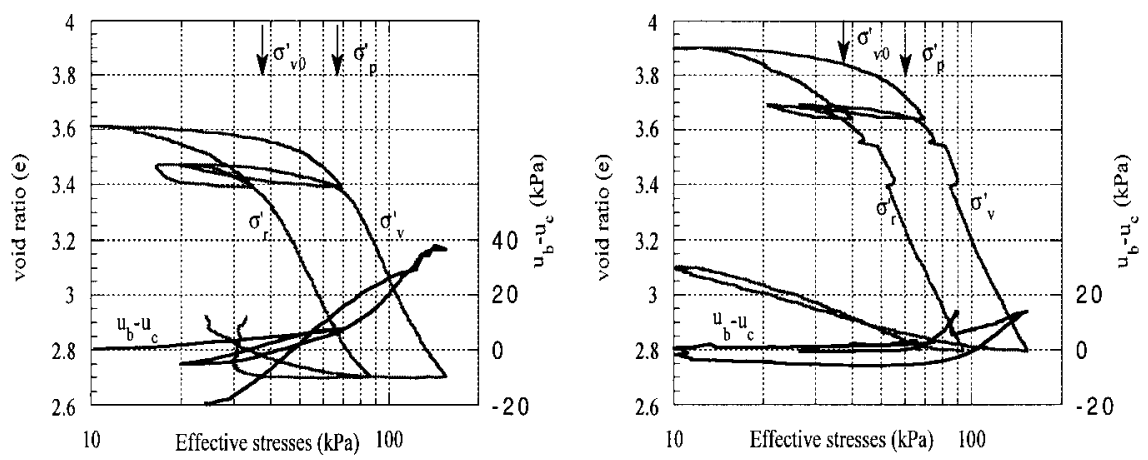

Fig. 9. One-dimensional consolidation test results for two specimens.

Table 6

Parameters of Saint Herblain clay specimens deduced from one-dimensional consolidation

\begin{tabular}{lllllllllll}
\hline Specimen & $C_{\mathrm{s}}$ & $\begin{array}{l}\kappa= \\
C_{\mathrm{s}} / 2.3\end{array}$ & $C_{\mathrm{c}}$ & $\begin{array}{l}\lambda= \\
C_{\mathrm{c}} / 2.3\end{array}$ & $\begin{array}{c}C_{\mathrm{s}} / C_{\mathrm{c}} \\
e^{2}\end{array}$ & $e_{\mathrm{o}}$ & $\begin{array}{l}\sigma_{\mathrm{p}}^{\prime} \\
(\mathrm{kPa})\end{array}$ & $\begin{array}{l}\varepsilon_{\mathrm{a}} \\
10^{-6} \mathrm{~s}^{-1}\end{array}$ & $\begin{array}{c}C_{\alpha e} \\
C_{\alpha \mathrm{e}} / \\
C_{\mathrm{c}}\end{array}$ \\
\hline 1 & 0.16 & 0.07 & 2.33 & 1.01 & 0.07 & 3.56 & 65 & 3.33 & \\
2 & 0.14 & 0.06 & 2.77 & 1.15 & 0.04 & 3.85 & 60 & 0.66 & 0.14 & 0.05 \\
\hline
\end{tabular}

We can note the high values of the initial void ratio (between 3.56 and 3.86), and of the compression index $C_{\mathrm{c}}$ (between 2.33 and 2.77) for the two specimens. Results obtained on the two specimens are comparable and representative of a highly plastic clay.

We know that the value of the preconsolidation pressure is affected by the strain rate [22-24]. In order to derive the value of the preconsolidation pressure for the strain rate of $2 \times 10^{-4} \mathrm{~s}^{-1}$, corresponding to the average strain rate at the cavity wall during the pressuremeter test, we used the following relation [24]:

$$
\begin{aligned}
\sigma_{\mathrm{p}\left(\varepsilon_{\mathrm{a}}\right)}^{\prime} & =\sigma_{\mathrm{p}\left(\varepsilon_{\mathrm{a}} o\right)}^{\prime}\left[\frac{\varepsilon_{\mathrm{a}}}{\varepsilon_{\mathrm{a} 0}}\right]^{\frac{C_{a \mathrm{e}}}{C(C-C \mathrm{CS}}} \\
\sigma_{\mathrm{p}}^{\prime} & =60\left(\frac{2 \times 10^{-4}}{0.66 \times 10^{-6}}\right)^{\frac{0.14}{2.77-0.14}} \\
\sigma_{\mathrm{p}}^{\prime} & =81 \mathrm{kPa}
\end{aligned}
$$

Having determined the values of $\lambda, \kappa$ and $\sigma_{\mathrm{p}}^{\prime}$ (note that the value of $\sigma_{\mathrm{p}}^{\prime}$ was considered close to that of $p_{\mathrm{c} 0}^{\prime}$ ), and assuming that the initial stress state is defined at $7 \mathrm{~m}$ depth by:

$$
\begin{aligned}
-\sigma_{\mathrm{r} 0} & =\sigma_{\theta 0}=p_{0}=70 \mathrm{kPa} \\
-\sigma_{\mathrm{v}} & =105 \mathrm{kPa} \\
-u_{\mathrm{c}} & =50 \mathrm{kPa}
\end{aligned}
$$


we can now apply the identification procedure to the pressuremeter test in order to determine the values of the two remaining parameters $G$ and $M$. We can see in Fig. 10 that we have a very close agreement between calculated and experimental curves.

The values of the shear modulus $G$ and of the critical state constant $M$ obtained from the optimisation procedure are respectively $705 \mathrm{kPa}$ and 1.19 . This last value is

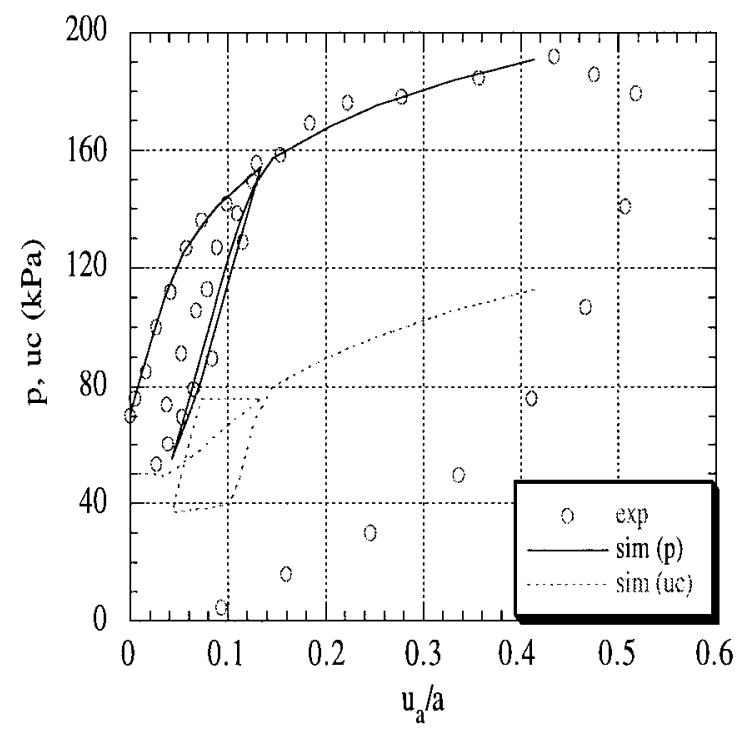

Fig. 10. Application results of the numerical process to identify $G$ and $M$ from pressuremeter test on Saint-Herblain clay at $7 \mathrm{~m}$ depth.

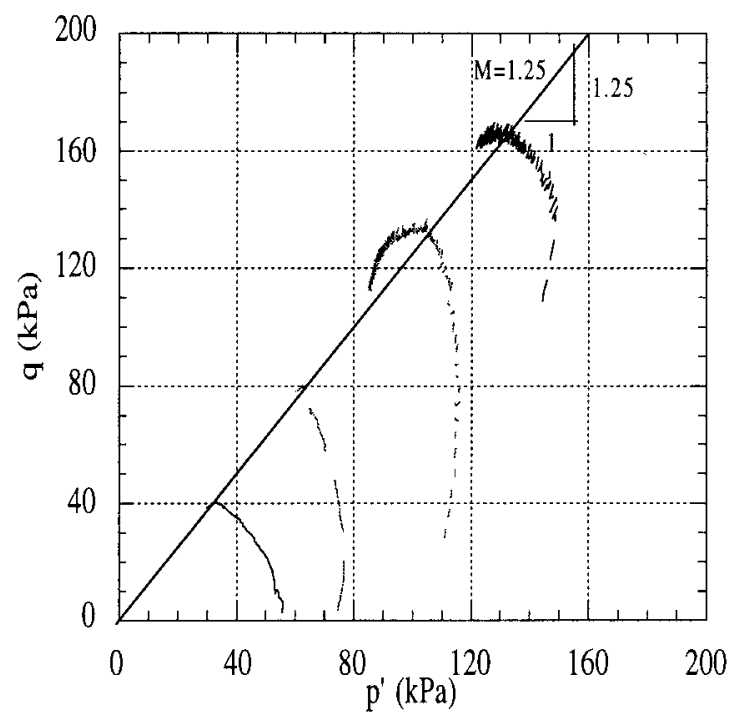

Fig. 11. Results of the triaxial tests (CU) on Saint-Herblain clay. 
Table 7

Identification of Cam-Clay parameters

One dimensional consolidation test

$\lambda, \kappa, p^{\prime}{ }_{\mathrm{c} 0}$

Pressuremeter test

$E, M$

${ }^{\mathrm{a}} p_{\mathrm{c} 0}^{\prime}$ can also be obtained from pressuremeter tests if the pore water pressure is measured during the test.

found to be close to the one deduced from triaxial tests (CUC) on Saint-Herblain Clay at the same depth as shown in Fig. $11(M=1.25)$.

We can therefore propose a methodology of the identification of Cam-Clay parameters based on data obtained from two tests: one-dimensional consolidation test and pressuremeter test. The main advantage is that these two tests can be considered as routine tests for geotechnics projects. Table 7 summarizes the approach.

\section{Conclusions}

In this study, our aim was to develop a complete inverse method which could be applied to various problems dealing with geomechanics, by associating a finite element code with an optimization code. In the present paper we applied this method to the identification of soil parameters by using in-situ testing, i.e. the pressuremeter test.

The resolution of the inverse problem of the cylindrical cavity expansion in an elastoplastic medium showed the ability of the method to determine soil parameters wherever the modified Cam-Clay model was used.

The parametric study of the pressuremeter test calculation with the finite elements method lighlighted the influence of each parameter on the numerical response. From these results, we proposed to use the pressuremeter results in order to determine the most influential ones.

This study revealed the difficulty in the inverse analysis to define parameters whenever a strong coupling exists between them.

In the case of a coupling between $E$ and $v$ because of the test type (purely deviatoric), the inverse analysis cannot be used to identify these two parameters simultaneously.

In the case of coupling between $M$ and $p_{\mathrm{c} 0}^{\prime}$, the problem can be solved by considering the pore water pressure as complementary information in the calculation of the pressuremeter test. The application on pressuremeter tests performed in SaintHerblain clay confirmed the ability of the proposed procedure to identify the shear modulus $G$ and the critical state constant $M$. This study showed that the parameters values deduced from the pressuremeter test optimization are close to those deduced from classical laboratory tests, in particular the triaxial test.

We can therefore propose a methodology of Cam-Clay parameters identification based on the data obtained simultaneously from one-dimensional consolidation tests and pressuremeter tests, considered as routine tests in geotechnics projects. 
The method can be generalized to different in-situ testing and also to other constitutive models, provided that the values of the parameters to be determined have a significant influence on the results of the finite elements calculation of the given insitu test. The number of parameters which can be derived from inverse analysis depends on the available number of in-situ tests on the same soil and on the number of variables measured during each test.

\section{References}

[1] Ménard L. Mesures in situ des propriétés physiques des sols. Annales des Ponts et Chaussées 1957;3:357-76.

[2] Ménard L. The interpretation of pressuremeter test results. Sols-Soils 1975:26.

[3] Ménard L. Calcul de la force portante des fondations sur la base des résultats desessais pressiométriques. Sols-Soils 1963;5:9-24.

[4] Amar S, Jézéquel J-F. Essais en place et en laboratoire sur sols cohérents, comparaison des résultats. Bull. Liaison des Lpc. 1972;58.

[5] Baguelin F, Jézéquel J-F. Le pressiomètre autoforeur et le calcul des fondations. Design Parameters in Geotechnical Engineering 1979;185-90.

[6] Bishop RF, Hill R, Mott N-F. The theory of identation and hardness test. Proc Physical Soc, London 1945;N57:147-59.

[7] Gibson RE, Anderson WF. In situ measurements of soils properties with the pressuremeter. Civ Engng Publ Wks Review 1961;56(658):615-8.

[8] Salençon J. Expansion quasi-statique d'une cavité à symétrie sphérique oucylindrique dans un milieu élastoplastique. Annales des Ponts et Chaussées 1966;iii:175-87.

[9] Vesic AS. Expansion of cavities in finite soil mass. Journal of Soil Mechanics and Foundation Engineering Division, ASCE 1972;98(3):265-90.

[10] Pasturel D. Essais de chargement de pieux dans la craie altérée. Bull de Liaison de LCPC, Paris 1968;29:1-24.

[11] Monnet J. Analyse théorique et expérimentale de l'équilibre élasto-plastique d'un solcohérent autour du pressiomètre. In: The Pressuremeter and its Avenues. Rotterdam: Balkema, 1995. p. 193-200.

[12] Cambou B, Boubanga A, Bozetto P, Haghgou M. Determination of constitutive parameters from pressuremeters tests. In: 3rd Symposium on the Pressuremeter and its Marine Applications. Oxford University, 1990.

[13] Bahar R, Cambou B, Costaz JL, Fry JJ, Bufi G, Patel P. Prediction of longterm settlement of nuclear power plants using pressuremeter tests. Proceedings of Numog IV 1992;2:851-9.

[14] Soegiri S. Modélisation de l'essai pressiométrique avec prise en compte del'interaction fluide-solide. Application a l'identification du comportement des sols. Thèse de doctorat, Ecole Centrale de Lyon, 1991.

[15] Hicher PY, Michali A. Identifying soil parameters by means of laboratory and in-situ testing. Computer and Geotechnics 1996;19(2):153-70.

[16] Pilvin P, Cailletaud G. Identification and inverse problems related to material behaviour. In: Bui Tanaka, et al., editors. Inverse Problems in Engineering Mechanics. Rotterdam: Balkema, 1994. p. 79-86.

[17] Nougier JP. Méthodes de calcul numériques. Paris: Edition Masson, 1985.

[18] Roscoe KH, Burland JB. On the generalise stress-strain behaviour of wet clay. In: Engineering plasticity. Cambridge, 1968. p. 535-609.

[19] Nahra R, Frank R. Contributions numériques et analytiques a l'étude de laconsolidation autour du pressiomètres. Rapport de Recherche Lpc, 1986;137.

[20] Accar YB, Tumay MT, Chan A. Interpretation of the dissipation of penetration pore pressure. In: Proc. Int. Symp. on Numerical Models in Geomechanics, Zurich, 1982. p. 353-8. 
[21] Mieussens C, Magnan JP, Soyez B. Essais de compressibilité àl'oedomètre. Procédures recommandées par les Laboratoires des Ponts et Chaussées. Bull Liaison Labo P et Ch 1985;139:5-18.

[22] 3Leroueil S. Magnan, JP, Tavenas F. Remblais sur Argiles Molles. Edition Lavoisier, 1985.

[23] Mesri G, Hayat TM. The coefficient of earth pressure at rest. Can Geotech Journal 1993;30:647-66.

[24] Moulin G. Etat limite d'une Argile Naturelle, L'argile de Pornic. Thèse de doctorat, E.N.S.M deNantes, 1988. 